\title{
Effect of Pile's Number on the Behavior of Piled Raft Foundation
}

\author{
Dheyaa H. Hadi ${ }^{\mathrm{a}^{*}}$, Mohammed Y. Fattah ${ }^{\left(\mathbb{D}{ }^{\mathrm{b}}\right.}{ }^{\text {, Mohanned Q. Waheed }}$ \\ ${ }^{a}$ Civil Engineering Department, University of Technology, Baghdad, Iraq. \\ 42355@student.uotechnology.edu.iq \\ ${ }^{\mathrm{b}}$ Civil Engineering Department, University of Technology, Baghdad, Iraq.40011@uotechnology.edu.iq \\ ${ }^{c}$ Civil Engineering Department, University of Technology, Baghdad, Iraq. 40094auotechnology.edu.iq \\ *Corresponding author.
}

Submitted: $12 / 08 / 2020$

Accepted: 16/01/2021

Published: 25/07/2021

\section{K E Y W O R D S}

Piled-raft, Number of piles, Pile spacing, Sand density.

\begin{abstract}
A B S T R A C T
This paper introduces an experimental research on the behavior of the piled raft foundation (PRF) in sand of two states (loose and medium sand). A small model has been tested in a soil container and the vertical load was applied to the foundation through a pneumatic jack. The settlement of the foundation was measured using a displacement transducer; three sensors were attached to the pile heads to measure the axial load borne in a group by each pile by the Arduino data logger. The laboratory experiments were carried out on models of (1 pile), (1x2), (1x3), (2x3), (3 x3), (3 piles triangular), (4 piles diamond), (5 piles), and (9 pile circle), as well as to tests on an unpiled raft. Test variables were pile length, number of piles, and sand density. It is noticed that when the piles increased to nine piles in the group, the bearing capacity increased by $40 \%$. The effect starts to increase when one pile is just placed under the raft as the bearing capacity of the piled raft increased by $3 \%$ and $7 \%$ when the pile length is $15 \mathrm{D}$ and, $20 D$, respectively. The reduction in the settlement is also observed to be smaller and no economic advantage is achieved with more increase in the number of piles. If the number of piles reaches (6) piles, the influence of the piled raft on settlement reduction disappears.
\end{abstract}

How to cite this article:D. H. Hadi, M. Y. Fattah and M. Q. Waheed, "Effect of Pile's Number on the Behavior of Piled Raft Foundation,” Engineering and Technology Journal, Vol. 39, No. 07, pp. 1080-1091, 2021.

DOI: https://doi.org/10.30684/etj.v39i7.1795

This is an open access article under the CC BY 4.0 license http://creativecommons.org/licenses/by/4.0

\section{INTRODUCTION}

In foundation engineering, raft foundations or pile foundations are usually the most common kinds of foundations performed in large buildings or structures. Such systems can meet the design criteria when implemented alone; nevertheless, they are in most situations over-safe and inefficient economically. Besides, they can cause some serious problems in some cases when used alone. On the other hand, these systems can be combined if the conditions are suitable and one can have a more effective, safe, and inexpensive design. Therefore, the piled raft foundation (PRF) is one such combined system. This system of foundations consists of three elements: raft, soil, and piles. The 
mechanism of interaction between these elements is very complex, containing the interaction of PileSoil, Pile-Soil-Pile interaction, Raft-Soil interaction and finally the interaction of Pile-Raft.

\section{Previous Studies}

Lots of literatures are reported. Some of the main literatures directly linked to this paper will be reviewed and discussed here. Cooke (1986) showed a comprehensive number of small-scale model test in stiff clay on "unpiled raft, free standing pile groups and piled raft (P-R)" of different sizes. It was noticed that the stiffness of theP-R was as much as 30 percent higher than that of the "freestanding pile's group", while the "piled raft" load-carrying capacity was higher than that of the "freestand pile group" the results identified the influence of piles length on the behavior of the PRF, andnoted that piles must be tall enough in proportion to the dimensions of the raft. It was also concluded that the sharing of the load among the piles of PRF in the situation of a rigid raft based on the number and spacing of the pile [1].

Phung (1993) [2] carried out a large-scale field study on "shallow footings, isolated piles, freestanding pile groups, and piled rafts(P-R)" in sandy soil with different densities. It was noticed that $\mathrm{P}-\mathrm{R}$ foundation behavior is ruled by the P-R relationship, because of the contact pressure induced between the raft and the soil beneath it, the capacity of the pile shaft increased. It was observed that the piled rafts, center pile always takes up the greatest portion of the load.

Katzenbach and Reul (1997) [3] described a theoretical model that allows the different loadsettlement behavior of the piled raft and the raft-soil, raft-pile, and pile-pile interactions to be investigated. The authors showed that the loading on the raft caused an increase in normal stresses among the soil and the pile shaft. The piles in the piled raft foundation developed a shaft resistance more than double that in the pile within a normal group or a single isolated pile. The middle piles showed the highest values.

Al-Tameemi (2011) [4] examined the behavior of P-R systems in sandy soil with various densities. Small models were tested in a sandbox with a pressure jack attached to the foundation and the load measured using the load cell.It was indicated that by continuing to add piles to the group under the raft, it reduced the amount of decrease in the settlement, and using piles as a settlement reducer is neither reasonable nor economical. Use of a cushion layer under the pile cap contributes to an increase in the failure load of the PR. Increased failure loads of about 80 percent and 28 percent can be achieved for $(3 \times 3)$ and $(4 \times 4)$ configuration, when the larger cushion is extended to a distance of two pile diameters beyond the cap. On the other hand, this cushion will contribute to a reduction of around 160 percent and 64 percent, respectively in settlements.

Juneja (2013) [5] studied the effects of the raft thickness, length, and number of piles on the loadsharing ratio by the piles. Model tests of $(1 \mathrm{~g})$ were performed, the piles load was measured from the model tests and calculated theoretically from the piled raft coefficients. It has been found from the tests that the total piles load decreased when the load increased. The load-carrying capacity of the piles increased with the length of the center pile, for further piles, the loads were approximately the same with different raft thicknesses. The contribution of the raft increased when the number of piles decreased.

Fattah et al. (2013) [6] carried out Conducted numerical investigation of the consolidation settlement (PRF) in clay, and established excess pore water pressure (EPWP) dissipation and its effect on the load-carrying capacity of (PRF) is performed by means of the Finite Element Method (FEM). The soil is symbolized by the "modified Drucker-Prager/cap model" and the ABAQUS computer application is used.The (FE) analysis simulates 5 different pile group geometries. It was noticed that because of the dissipation of (EPWP) the settlement below the (PRF) considerably influences the total settlement of the foundation, and the change of displacement over time should receive greater attention. The unpiled raft load-settlement curve showed the profile in the bowl shape with a maximum settlement at the center. With a reduction in thickness of the raft, the curvature increases under vertical load increases. The stability of the raft differential in dimensions $(10 \mathrm{x} 10 \mathrm{~m})$ for the same vertical load decreases by more than $90 \%$ if the thickness of the raft increases from $0.75 \mathrm{~m}$ to $1.5 \mathrm{~m}$. The average load carried by piles depends on the number of piles in the group.

Waheed (2016) [7] investigated the P-R behavior in clayey soil and investigated the possibility to evaluate the sharing load among the (PRF) elements. It was observed that the piles that carry most of the applied load (70-80 \%) during the stage of initial loading until about $30 \%$ of the ultimate P-R capacity, the pile capacity stays stable, and the share of raft load increases slowly. It was also found 
that the (PR) foundation's ultimate load capacity is inadequate to the value of the raft's ultimate capacity plus all the piles.

Sahraeian (2018) [8] performed a set of centrifuge model's experiments to analyze the mechanical behavior of oil tanks placed on a P-R foundation system on Saturated liquefied sand and dry, non-liquefied sand. Two forms of foundations were tested; a slab foundation (SF) and a PRF. The centrifuge model test results showed that the input motions of both foundation types were amplified in dry sand, but the amplification of the piled raft foundation was longer than the slab foundation. The lower confinement effect of (P-R) foundation raft stress than that of slab foundation has made the normal duration of the sub-soil for (P-R) foundation longer than that of the slab foundation. The loads and the rotational moment carry both the raft and the pile resistance.

The PRF will efficiently minimize rocking motion of the tank, settling, and irregular tank settlement.

Husein (2020) [9] discussed the effects of piles number, groundwater level, piles spacing and the raft thickness on the behavior of load-settlement of piled-raft foundation in sandy soil under vertical load using both full-scale tests and finite element analysis. It was noticed that by increasing the number of piles and spacing, the bearing capacity of the piled raft system increased without any significant effect of the raft thickness. The settlement increased by the presence of water.

The main goal of the experimental research accomplished during this paper is to examine the behavior of the piled raft foundation has various numbers of piles, piles length and different soil densities. The next sections explain the load test system needed to conduct the model tests, the pile configurations in the P-R models, the properties of the used material, the research plan and the test procedures.

\section{MATERIALs, EqUiPMENT, AND TEST SetuP}

\section{Axial loading system}

The axial loading system consists of different parts as illustrated in Figure 1: Pneumatic loading jacks, steel frame, piled raft models and steel container. The loading system involves 2 jacks; the main one is named "high range jack (jack 1)", which applies vertical load from ( $375 \mathrm{~N}$ to $1171.9 \mathrm{~N})$. On the opposite, it is referred to as a "low-range jack (jack 2)", which applied vertical loads between $(153.7 \mathrm{~N}$ and $442 \mathrm{~N})$. The two forms are illustrated in Figure 2. Both vertical loading jacks are used consistent with the load to be applied by pressure gauge measurements as shown in Figure 3. Displacement transducers (VL53LOX) have been used for measuring the settlement of the foundation system. The VL53L0X uses flight sense technology (ST) to accurately estimate how long it will take to reach the nearest target for emitted infrared laser pulses to be reflected to the detector. Three A201TEKSCAN [10] type flexiforce sensors were used to measure the axial force in the piles; these sensors are with $0.203 \mathrm{~mm}$ thickness, flexible, lightweight, low-power, customizable, and accurate. They can measure force between almost any two surfaces and are durable enough to stand up to most environments. These sensors attached to the piles head and connected to a data logger from the Italian company of Arduino supporting electrical circuit with up to 16 ports as shown in Figure 4.

\section{Soil tank}

The soil box has interior dimensions of $(600 \times 600 \times 500)$ millimeters and has solid partitions to avoid the lateral movement of the soil. It should be remembered that the dimensions of the box were well aligned with the vertical stress distribution as the width of the model raft would be $112 \mathrm{~mm}$ and the effective pressure distribution would be increased to 2 to 3 times the width, i.e. $224-336 \mathrm{~mm}$. As a result, the layout can be said to be an elastic half-space (Yilmaz, 2010) [11],and no interaction will occur between the partitions of the container and the failure zone about the P-R model. 


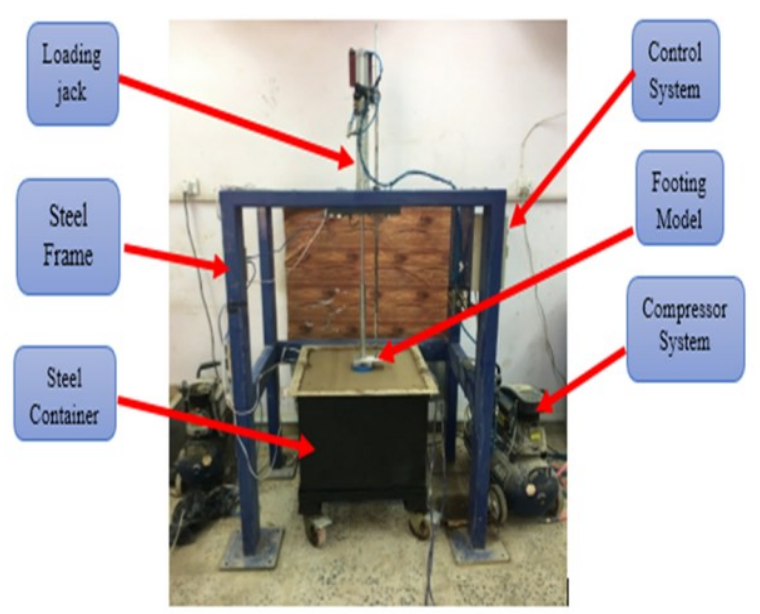

Figure 1: Axial loading system

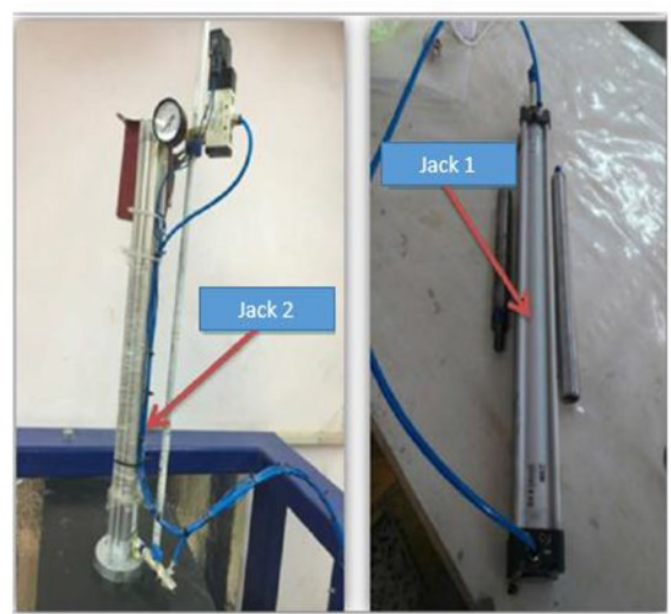

Figure 2: Loading jack

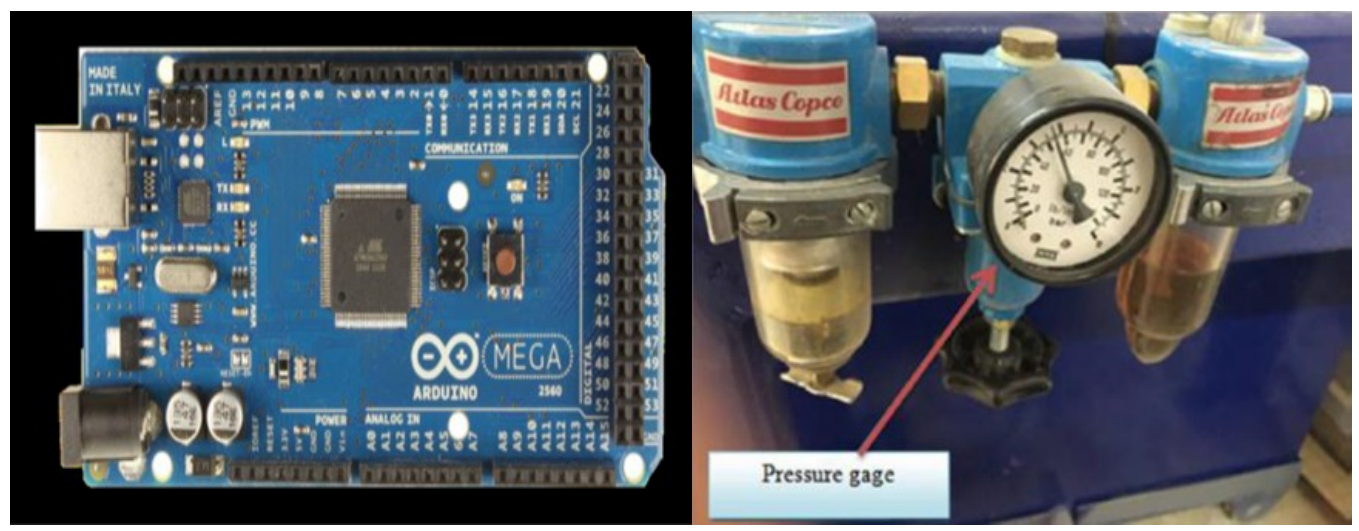

Figure 3: Datalogger Figure 4: Pressure measurement device

\section{Properties of soil}

Soil for the model's analysis is dry, clean, and poorly gradedsand,standard tests were performed on the sand having two relative densities; loose and medium. Table I shows the sand tests carried out with specifications. The grain size distribution of sand is shown in Figure 5. The physical properties of the test sand are described in Tables II and III. The direct shear apparatus used to get the angle of internal friction $(\phi)$ for two sand densities. 
TABLE I: Specifications of tests carried out on sand.

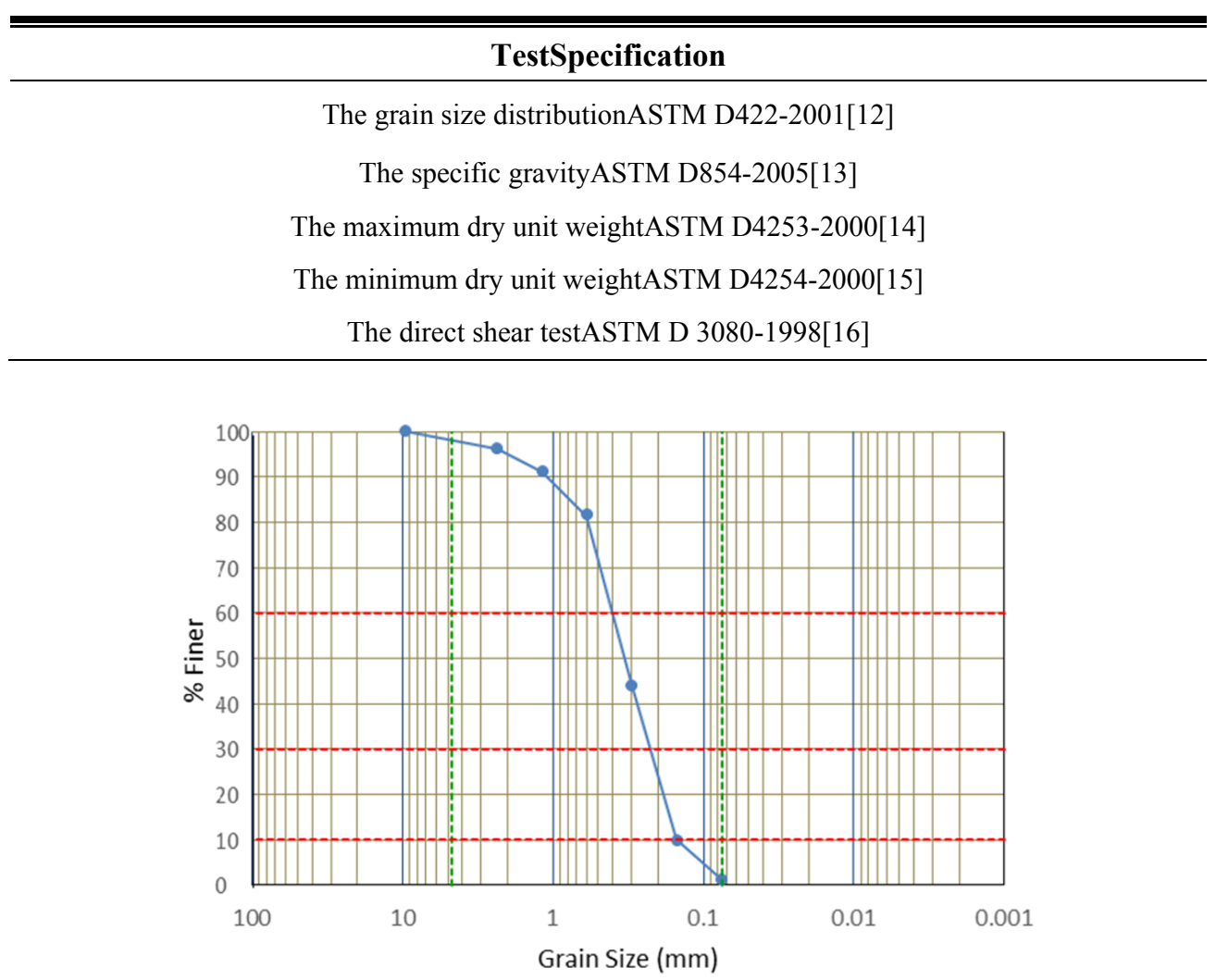

Figure 5: Grain size distribution of the sand

TABLE II: Selective properties for the tested sand.

\begin{tabular}{ccccc}
\hline \hline $\begin{array}{c}\text { Type of } \\
\text { sand }\end{array}$ & $\begin{array}{c}\text { Dry unit } \\
\text { weight }\left(\boldsymbol{\gamma}_{\boldsymbol{d}}\right)\end{array}$ & $\begin{array}{c}\text { Angle of } \\
\text { friction }(\boldsymbol{\phi})\end{array}$ & $\begin{array}{c}\text { Relative density } \\
\text { (R.D.) } \%\end{array}$ & $\begin{array}{c}\text { Void ratio } \\
\text { (e) } \%\end{array}$ \\
\hline Loose & $15.8 \mathrm{kN} / \mathrm{m}^{3}$ & 33 & 30 & 69 \\
\hline Medium & $16.5 \mathrm{kN} / \mathrm{m}^{3}$ & 38 & 60 & 62 \\
\hline
\end{tabular}

TABLE III: $\quad$ Tested sand physical properties.

\begin{tabular}{cc}
\hline Properties & Value \\
\hline Grain size analysis & \\
\hline Effective size, $\mathrm{D}_{10}(\mathrm{~mm})$ & 0.15 \\
\hline Mean size, $\mathrm{D} 50(\mathrm{~mm})$ & 0.32 \\
\hline Coefficient of uniformity, $\mathrm{C}_{\mathrm{u}}$ & 2.67 \\
\hline Coefficient of curvature, $\mathrm{C}_{\mathrm{c}}$ & 0.88 \\
\hline Classification $(\mathrm{USCS})^{*}$ & $\mathrm{SP}$ \\
\hline Specific gravity, Gs & 2.67 \\
\hline Dry unit weights & $17.8 \mathrm{kN} / \mathrm{m}^{3}$ \\
\hline Maximum dry unit weight, $\gamma_{\mathrm{d}(\max )}$ & $15.2 \mathrm{kN} / \mathrm{m}^{3}$ \\
\hline Minimum dry unit weight, $\gamma_{\mathrm{d}(\min )}$ & $38^{\circ}$ \\
\hline Angle of friction $(\phi)$ & $33^{\circ}$ \\
\hline At relative density R.D $=60 \%$ & \\
\hline At relative density R.D $=30 \%$ & 0.756 \\
\hline Void ratios & 0.49 \\
\hline Maximum void ratio, $e_{\max }$ & \\
\hline Minimum void ratio, $e_{\min }$ & \\
\hline
\end{tabular}




\section{Models of piled rafts}

Smooth aluminum pipes are the types of piles used in the research. The diameter of piles is 16 $\mathrm{mm}$. The embedment (length / diameter) ratio $\mathrm{L} / \mathrm{d}=15$ and 20 , the piles spacing is $\mathrm{S} / \mathrm{d}=2.5$ and 3 (The reason for choosing these values is to avoid increasing the dimensions of the soil container and to avoid the need to use a device with high loads). The ratio of the diameter of the pile is normalized to the mean particle size to be $\mathrm{Dp} / \mathrm{D} 50=50$ and it is sufficient to mitigate the influence of the grain size on the behavior of the interface as recommended by Vipulanandan et al. (1989) [17], the experiments were performed in sandy soil with a loose and medium relative density of 30 and 60 percent, respectively. The raft of the model is based on an aluminum foundation with dimensions of $(112 \times 112 \times 6) \mathrm{mm}$.

\section{Procedure of tests}

The following steps represent the method used to test the PR models:

\section{A. Creating a model of piled raft:}

Piles with aluminum pipes with fixed diameter and length were used to assemble eleven configurations of pile groups. The models were designed to perform an experimental study testing program as shown in Figure 6; to avoid the use of welding; very strong glue has been used to attach the piles to the raft foundation.

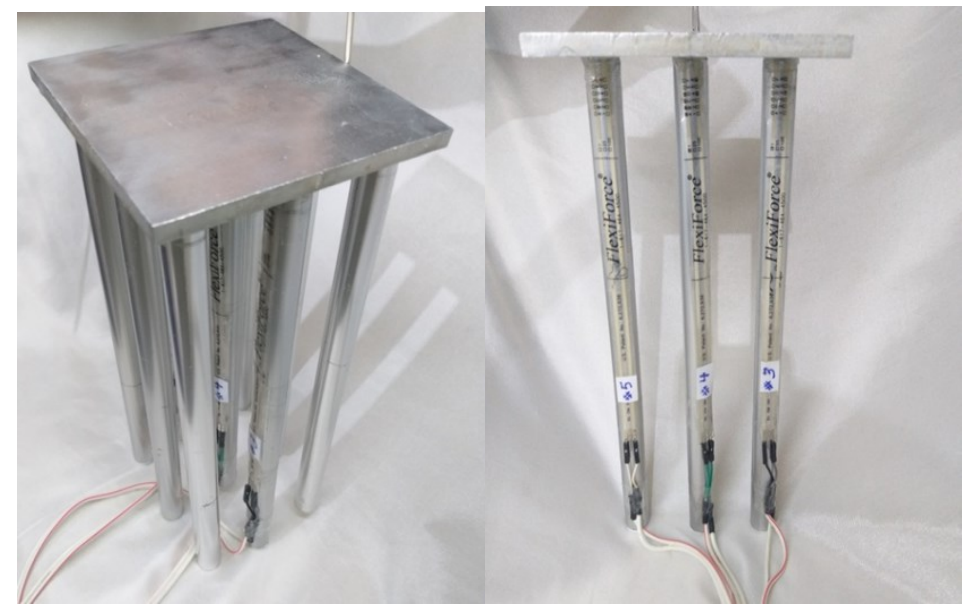

Figure 6: Models of piled raft

\section{B. Attachment of Flexiforce sensors FSR}

Two configurations of the instrumented model piles were assembled: The Force sensitive resistor (FSR) sensors were placed at the pile head, the instrument adopted provided measurement of the axial loads transferred to each instrumented pile. While the other FFS sensor is used for contact pressure measurements placed under the raft [18] \& [19], the tactile load sensors were not located in the soil; they were fixed to the pile cap surface by adhesive tape.

The image of FFS sensors and the instrumented model piles is shown in Figure 7 with very thin wires, linking the FFS sensors with an acquisition system.

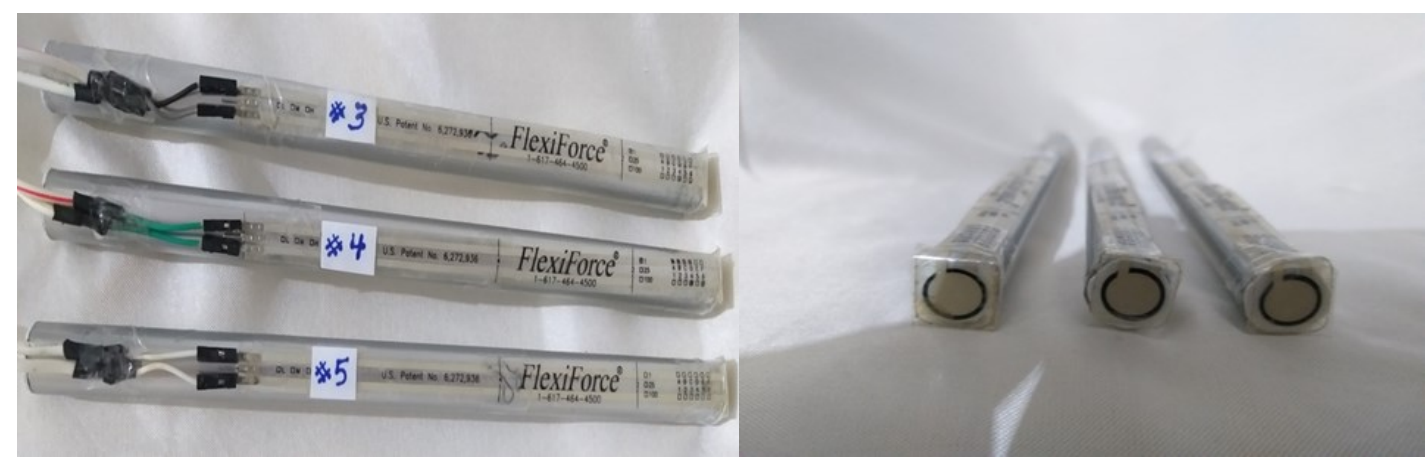

Figure 7: Attachment of sensors 


\section{Preparation of sand deposit}

Each test model was prepared after calculating the amount of soil needed for it using Equation (1) by calculating the dry unit weight at the specified relative density:

$$
D_{r}=\frac{\gamma d_{\max }}{\gamma_{d}} \times \frac{\gamma_{d}-\gamma_{d \min }}{\gamma d_{\max }-\gamma_{d \min }}
$$

Where:

$\gamma_{\mathrm{d}}$ : dry unit weight at the specified relative density,

$\gamma_{\mathrm{d}}(\min )$ : minimum dry unit weight, and

$\gamma_{\mathrm{d}}(\max )$ : maximum dry unit weight.

In order to ensure that the density along the model depth is constant, the soil container is divided intolayers with a $(50 \mathrm{~mm})$ height and each layer is adjusted and compacted manually until the line that defines the thickness of each layer is reached. The procedure is repeated till the target height of thesoil has been achieved. All layers shall be modified, and the tropical surface shall be checked horizontally to ensure that the soil does not lump in a certain area and that the foundation model is laid on a fully flat surface.

\section{Application of vertical load:}

Every soil model was reconfigured into two relative densities (R.D $=30 \%$ and $60 \%$ ), a layer of soil with a thickness of 7 times pile diameters (Dp) was furnished. After that, layers of sand are spread every $50 \mathrm{~mm}$ until reaching a height equal to $20 \%$., and compacting them to achieve the required density. The piled raft foundation was attached to the cylinder shaft of the pneumatic jack and was lowered slowly through the manual switch until contact between the base of the piles and the surface of the soil is reached.

The device is installed at this level and start filling the box with sand until it reaches a thickness that covers $80 \%$ of the pile length. After adjusting and leveling the surface, making sure that all the sensors are attached to the data logger.

The piled raft foundation was pressed until it penetrated the sand layer by $20 \%$ of the length of the pile as a result of this process a differential settlement of the surrounding soil occurs, so before the contact between the soil and the raft occurs, it is important to make sure to adjust the surface of the soil so that the sensors below the foundation are not affected by this differential settlement. After the contact occurs, the compression process stops. This pile installation technique was believed to be sufficient to completely mobilize the end bearing capacity, as the piles had at least penetrated $3.75 \mathrm{Dp}$ [20].

The loading shaft (piston) was lowered slowly until it will be in contact with the raft plate surface, and then the process of test was conducted till a relative pile settlement $\delta \approx 10 \%$ of raft length was exceeded, where $\delta$ is the measured settlement. Some of photos during the test are shown in Figure 8.

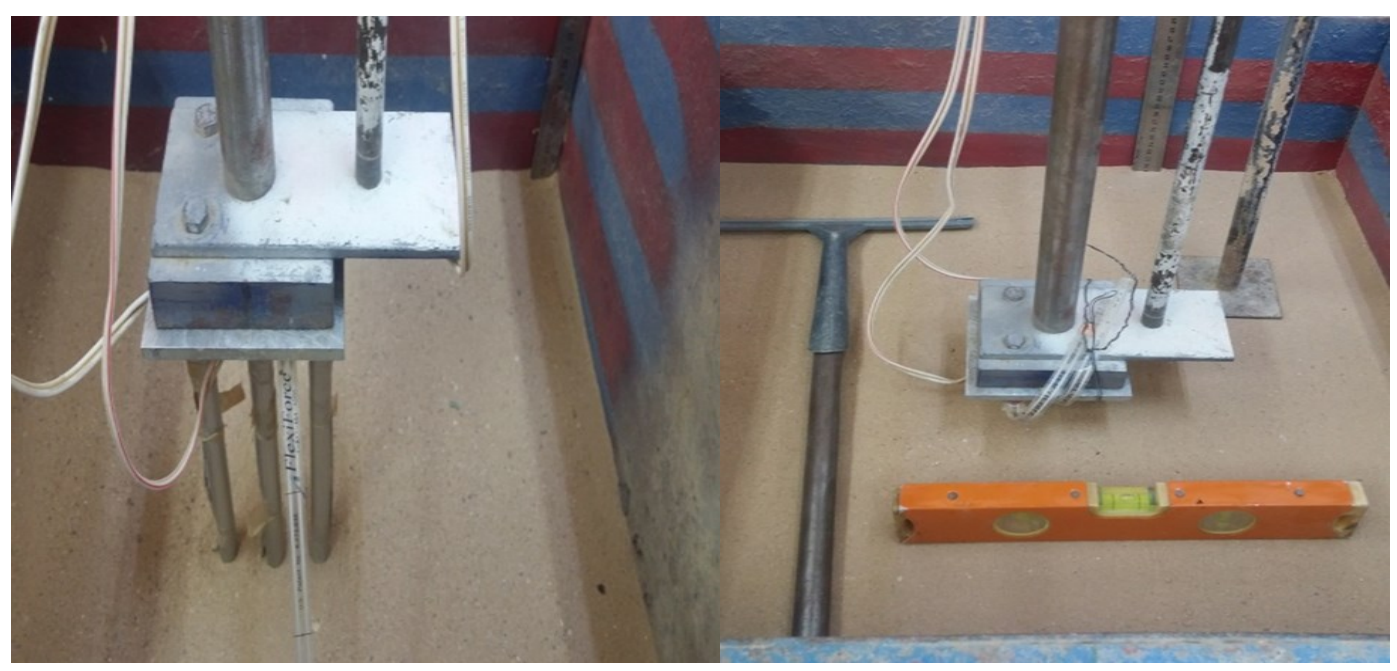

Figure 8: During the test photos 


\section{Discussion OF RESUlts}

The vertical load applied to the piled raft model is carried partially by the raft while the piles hold another portion. The amount of load transmitted by the piles to the total applied load can be calculated from the model's tests, by connecting piles to Flexiforce sensors to measure the axial load received by each pile. Rigid rafts were used to uniformly distribute the load onto the piles; the load can be measured in 3 piles. Because of the axial-symmetry of load and geometry, the piles mounted at the same radial distance from the center of the raft are believed to have the same load.

\section{Effect of pile length on the behavior of the P-R-F}

The load-settlement curves of the P-R models are shown in Figures 9 and 10. The applied load plotted vs. the settlement of the model normalized to the raft diameter $(\delta / \mathrm{dr})$. The pile's length $\mathrm{L}=$ $15 \mathrm{Dp}$ and $\mathrm{L}=20 \mathrm{Dp}$.

The figures show the effect of increasing the pile length on the behavior of the P-R foundation under concentrated applied load. The load settlement curve for every model result is detected to be nonlinear. The piled raft with short piles undergoes larger settlement than the raft of longer piles. In addition, the (PRF) with short piles reaches its maximum capacity with a small displacement, other than a (PRF) with a long pile where it reaches its maximum capacity with a greater displacement. Although from the load settlement curves shape shown in Figures 9 and 10, it appears that the local shear failure controls the piled raft failure in all model's tests.

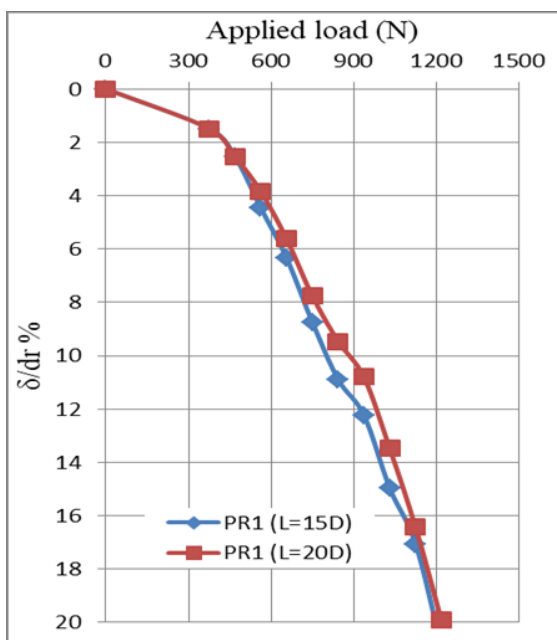

a. PR1

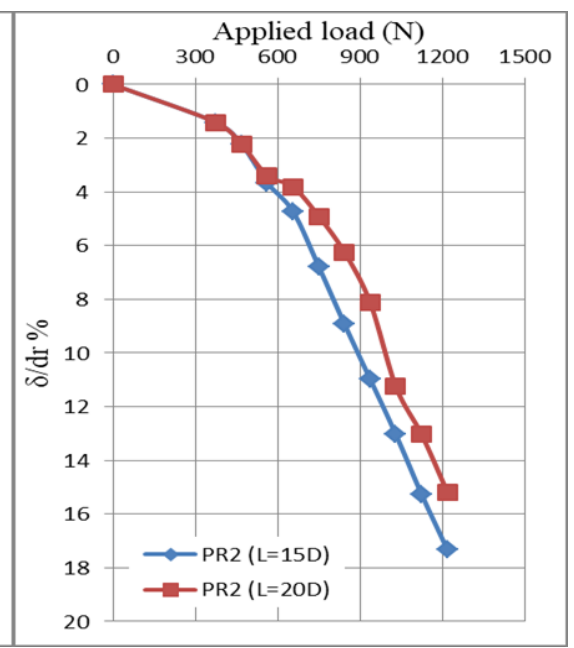

b.PR2

Figure 9: Effect of pile length on the behavior of piled - raft foundation (R.D. $=30 \%, S=3 D$ )

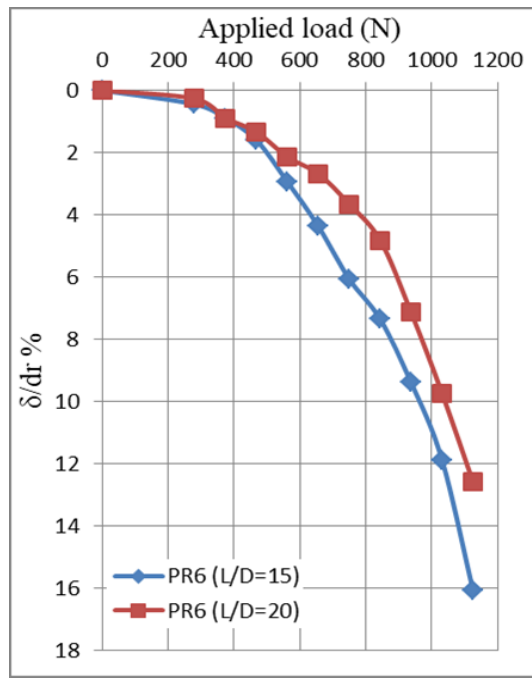

a. PR6

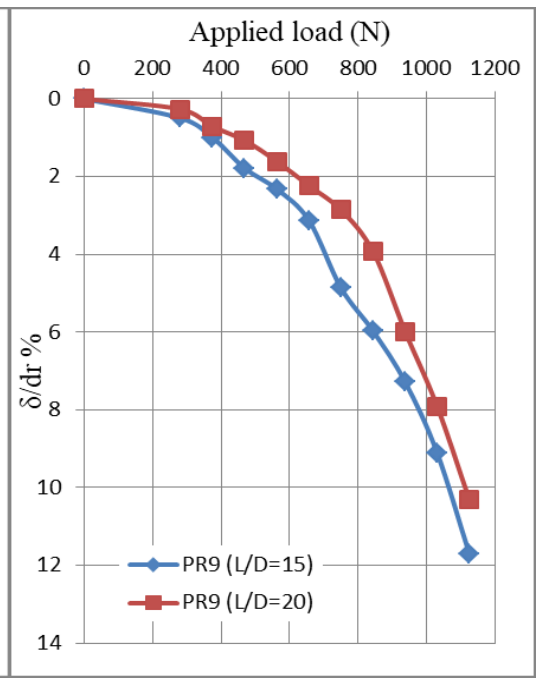

b. PR9

Figure 10: Effect of pile length on the behavior of piled - raft foundation (R.D. $=30 \%, S=3 D$ ) 
If the length of the piles has been changed from ( $\mathrm{L}=15 \mathrm{Dp}$ to $\mathrm{L}=20 \mathrm{Dp}$ ), it is likely to see more improvement in the (PR) foundation's load carrying capacity. It means that the results of increasing the pile length are to increase the bearing capacity of the (PRF).

The initial section of the curves for (PR) of different piles lengths indicates an overlap, at larger settlement, the (PRF) of piles of greater length holds more load than that with piles of smaller length. At the same relative settlement $(\delta / \mathrm{dr}), 10 \%$, the range of increasing in load carrying capacitywhen increase the pile length from $(240 \mathrm{~mm}$ to $320 \mathrm{~mm})$ for (PR1, PR2, PR4, PR5, PR6, PR9) modelsvaries from $(16 \%-20 \%),(29 \%-35 \%),(20 \%-31 \%),(28 \%-34 \%),(38 \%-44 \%)$ and, $(45 \%-48 \%)$, respectively.

Ai et al. (2020) [19] concluded that in comparison to pile length, the R-S stiffness ratio is not the main factor influencing the (PR) settlement. The raft settlement is reduced in the time domain as the pile length increases. For example, the initial settlement and final settlement decreases by 28.8 percent, 30.3 percent, respectively, as the pile-slenderness ratio ( $\alpha$ p) rises from 24 to 40 . The pile length influences primarily the loads from raft to side piles and central piles.

\section{Effect of number of piles on the behavior of the P-R-F}

It is known that increasing the number of piles within a group leads to increasing the loadcarrying capacity and decrease of settlement of the group. Figures 11 and 12 show that there is a clear increase in the foundation bearing capacity with the increase in the piles in the model, when the piles increased to nine piles within the group, the bearing capacity increased to $40 \%$. The effect starts to increase when just placed one pile under the raft as the bearing capacity of the piled raft increased to $3 \%$ and, $7 \%$ when the pile length $15 \mathrm{D}$ and, $20 \mathrm{D}$, respectively.

In contrast, Figures 13 and 14 also indicate that the piles act efficiently as a settlement reducer when the piles are higher than (6), the influence of the P-R foundation in decreasing the settlement disappears when the number of piles more than (6), this indicates that as the pile number increases further, the decrease in the settlement becomes smaller and no economic advantage is achieved.

This conclusion matches the conclusion of Yilmaz (2010) [11] and, Al-Tameemi (2011)[4] who found that the rise in the number of piles has no significant influence as concerns settlement, and there is an optimum number of piles that exceed this number, which does not substantially decrease settlement anymore. The results demonstrate that the confinement influence imposed by the adjacent piles induces an improvement in the ultimate value of the pile bearing capacity.

Fattah et al. (2015) [21] concluded that there is no significant contribution from the raft in a loadbearing capacity where a number of piles within the group is small (less than 4), because the area taken by piles relative to the raft is high. The failure load for a (PR) consisting of 9 piles is about 100 percent larger than the "free-standing pile group" including the same number. This contrast increases to about four times for a group of 16 piles.

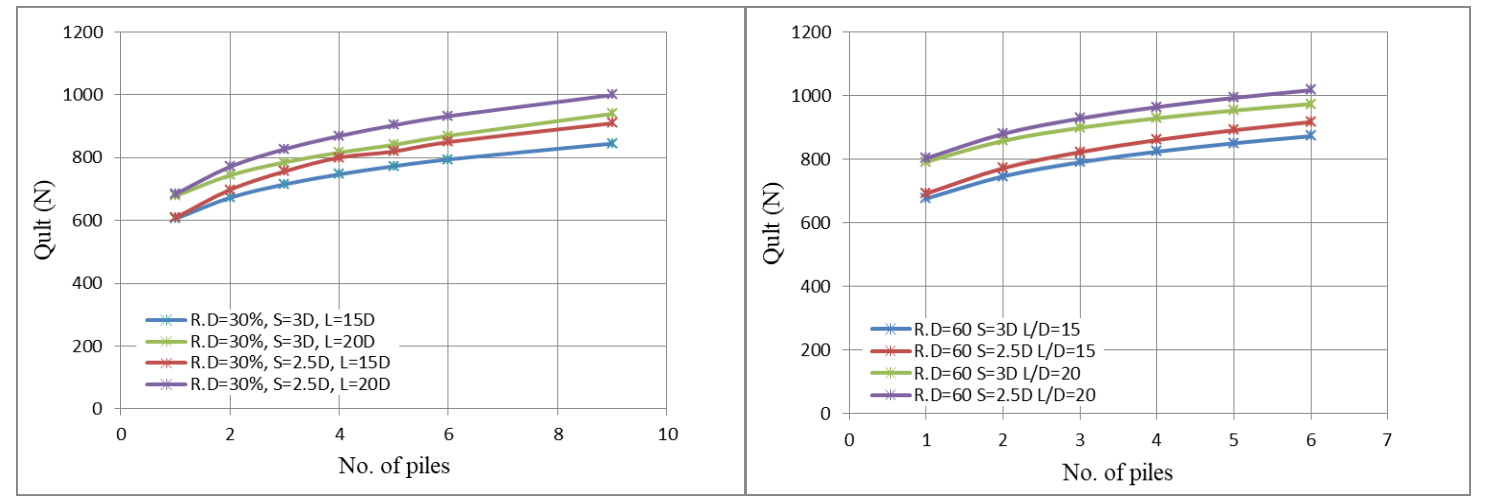

Figure 11: Effect of number of piles

on the ultimate load in loose sand
Figure 12: Effect of number of piles

on the ultimate load in medium sand 


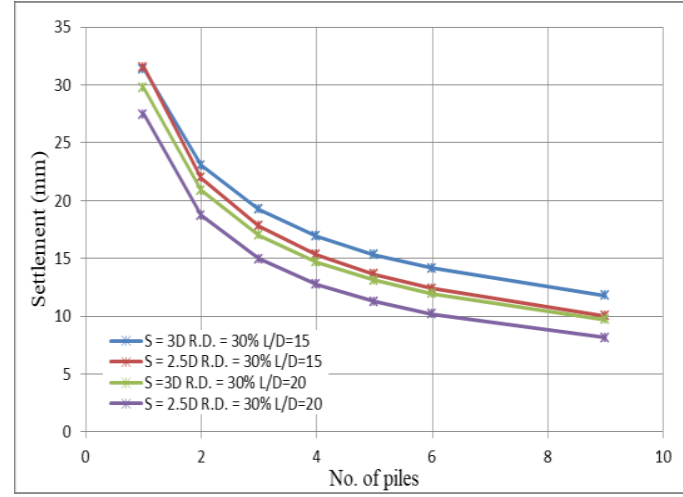

Figure 13: Effect of the number of piles on the settlement in loose sand

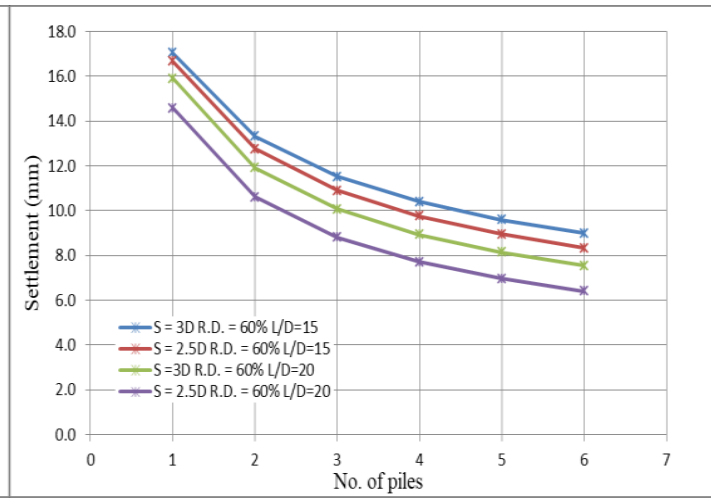

Figure 14: Effect of the number of piles on the settlement in medium sand

\section{Effect of sand density on the behavior of P-R-F}

In this section, (PR4) and (PR6) piled raft models are chosen to create a comparison among piled raft foundations embedded in loose and medium sand.

Figure 15 is drawn for (PR4) piled raft model embedded in loose and, medium sand, Respectively the figure illustrates that the ultimate bearing capacity of the (PR) increases by $12 \%$ for $L=15 \mathrm{D}$ and by about $14 \%$ for $\mathrm{L}=20 \mathrm{D}$. Figure 16 is drawn for $(2 \times 3)$ pile group embedded in loose and, medium sand, the figure show that the piled raft capacity increases by about $11 \%$ for $\mathrm{L}=15 \mathrm{D}$ and by about $10 \%$ for $\mathrm{L}=20 \mathrm{D}$.

This conclusion matches the conclusion of Al-Tameemi (2011) [4] who found that the ultimate load is increased by about $18 \%$ when the soil density changed from loose to medium and by about $39 \%$ when the soil density changed from medium to dense.

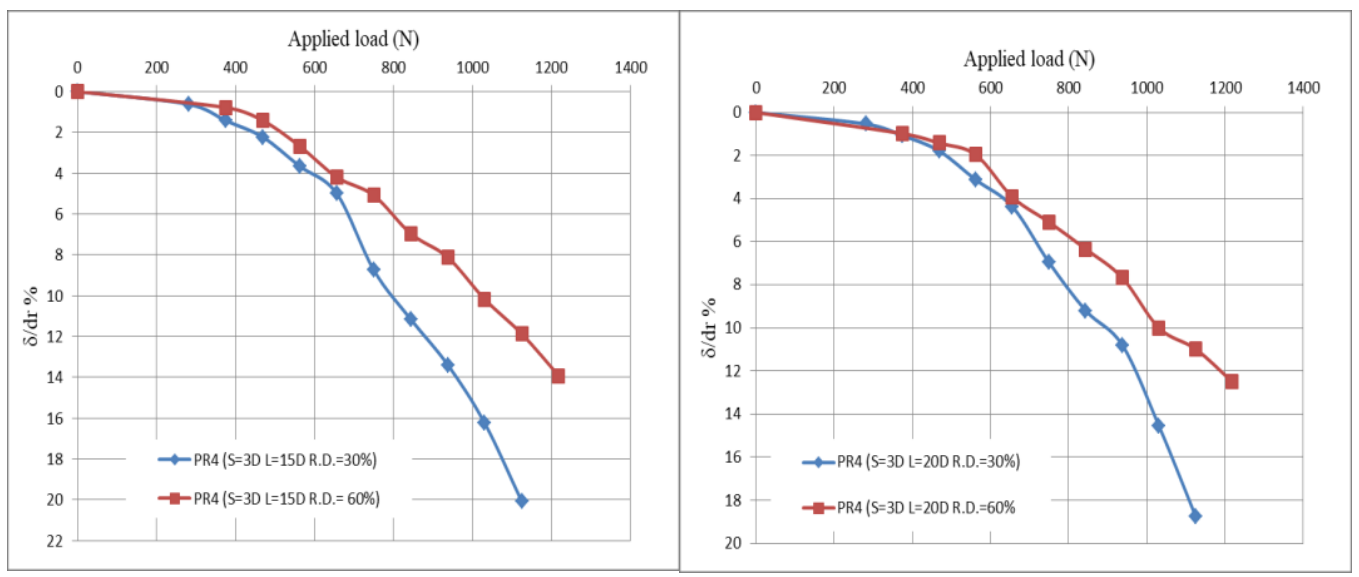

a. $L=15 D$ b. $L=20 D$

Figure 15: Effect of sand density (R. $D=30 \%$ and $60 \%$ ) on the behaviour of (PR4) (PRF) with different pile length 


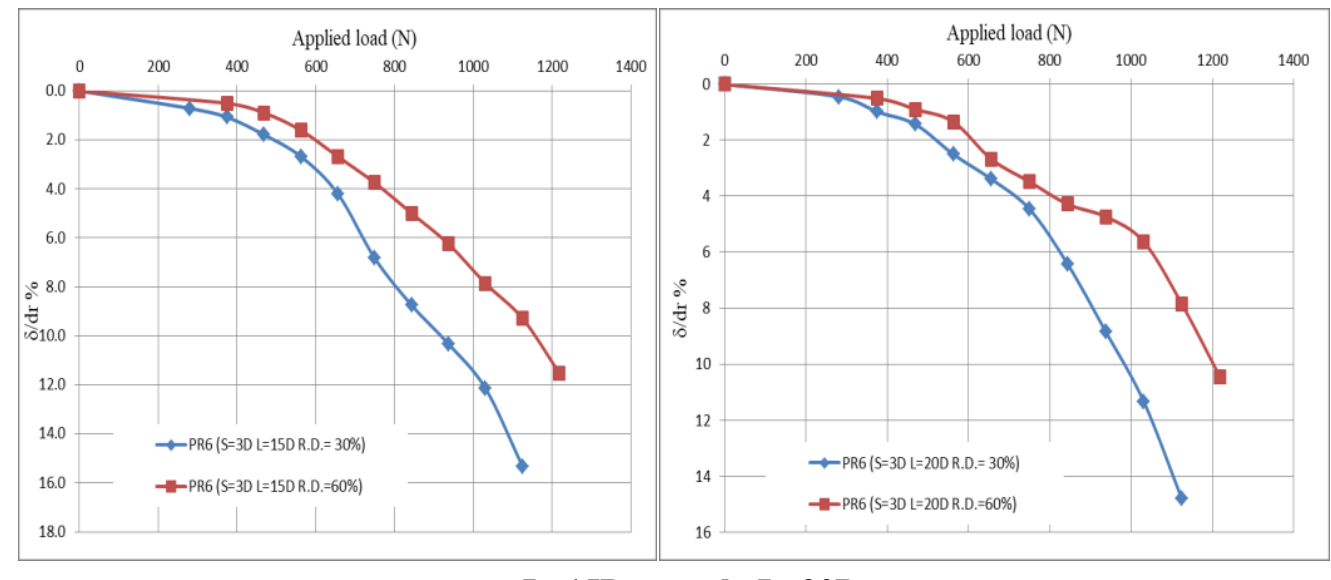

a. $L=15 D \quad$ b. $L=20 D$

Figure 16: Effect of sand density (R. $D=30 \%$ and $60 \%$ ) on the behaviour of (PR6) (PRF) with different pile length

\section{Conclusions}

1) The load displacement curve is seen to be non-linear for each model test. It appears that the local shear failure controls the piled raft failure in all model's tests.

2) The piled raft with short piles undergoes a larger settlement than the raft of longer piles. The (PRF) with short piles reaches its maximum capacity with a smaller displacement than that of the (PR) of longer piles.

3) When the number of piles within the group increased to nine piles, the bearing capacity is increased to $40 \%$.

4) The influence of the piled raft foundation in decreasing the settlement disappears when the number of piles of more than (6), this indicates that as the pile number increases further, the decrease in the settlement becomes smaller.

5) The initial section of the curves for (PR) of different piles lengths indicates overlap, at larger settlement, the (PRF) of piles of greater length holds more load than that with piles of smaller length. At the same relative settlement $(\delta / \mathrm{dr}) 10 \%$, the range of increasing in load carrying capacitywhen increase the pile length by $50 \%$ ranged between 16 and $48 \%$.

\section{REFERENCES}

[1] R. W. Cooke, "Piled Raft Foundations on Stiff Clays - a Contribution to Design Philosophy," Geotechnique, (1986), pp.169-203.

[2] D. L.Phung,"Footings with settlement-reducing piles in non-cohesive soil," Swedish Geotechnical Institute, Linköping, Report No. 43, (1993).

[3] R.Katzenbach, andO. Reul, "Design and Performance of PiledRafts," In Proceedings of the 14th International Conference on SoilMechanics and Foundation Engineering, (1997), Vol.4, pp. 2256-2256.

[4] S.M. Al-Tameemi, "Experimental Study for the Behavior of Piled Raft Foundation on Sandy Soil”, M.sc. Thesis, Civil Engineering Dept., Al-Mustansiriya Univ., Iraq, (2011).

[5] A.Juneja, A.Tyagi, \&R. Bisht, "Loadsharing in piled raft," Proceedings of Indian Geotechnical Conference,December, (2013),PP. 22-24.

[6] M. Y.Fattah, M. J. Al-Mosawi, A. A. O.Al-Zayadi, "Time Dependent Behavior of Piled Raft Foundation in Clayey Soil," Geomechanics and Engineering, (2013), Vol.5, No. 1, pp. 17-36.

[7] A. A.Al-Kaisi, F. H.Rahil, \& M. Q. WaheedDevelopment Bearing Capacity of Piles Embedded in Clayey Soil. Engineering and TechnologyJournal, (2018). Vol. 36, No.3A.

[8] S.M.S.Sahraeian, J.Takemura, and S.Seki, "An investigation about seismic behavior of piled raft foundation for oil storage tanks using centrifuge modeling," Soil Dynamics and Earthquake Engineering, (2018), Vol.104, pp.210-227.

[9] H.H.Hussein, H.H. Karim, andK.T. Shlash, "Analysis of piled raft foundation in sandy soil using full scale models,” MS\&E, (2020), Vol.1, pp.102-112. 
[10] B.Yilmaz, "An Analytical and Experimental Study on Piled Raft Foundations," MSc. Thesis, Middle East Technical Univ., Turkey, (2010).

[11] American Society for Testing and Materials, ASTM D422, "Standard Test Method for Particle SizeAnalysis of Soils,"2001.

[12] American Society for Testing and Materials, ASTM D854, "Standard Test Method for Specific Gravity of Soil Solids by Water Pycnometer,” 2005.

[13] American Society for Testing and Materials, ASTM D4253, "Standard Test Method for Maximum Index Density and Unit Weight of Soils Using a Vibratory Table,” 2000.

[14] American Society for Testing and Materials, ASTM D4254, "Standard Test Method for Minimum Index Density and Unit Weight of Soils and Calculation of Relative Density,"2000.

[15] American Society for Testing and Materials,ASTM D3080, "Standard Test Method for Direct Shear Test of Soils under Consolidated Drained Conditions,"1998.

[16] C.Vipulanandan, D. Wong, M.Ochoa, \& M. W.O'Neill, "Modelling of displacement piles in sand using a pressure chamber," In Foundation engineering: Current principles and practices, (1989), PP. 526-541.

[17] D.Giretti, "Modeling of piled raft foundation in sand," Ph.D. Thesis. Univ. of Ferrara. Italy,(2009).

[18] A. N., Najim, M. Y., Fattah, \& M. K., Al-Recaby “Cyclic Settlement of Footings of Different Shapes Resting on Clayey Soil”, Engineering and Technology Journal, (2020). Vol. 38, No. 3A.

[19] H. H.Karim, Z. W.Samueel, \&, A. H. Jassem, "Influence of Fly Ash Addition on Behavior of Soft Clayey Soil”, Engineering and Technology Journal, (2020). Volume 38, No 5A.

[20] Z. Y.Ai, Z. H.Chu, \& Y. C.Cheng, "Time effect of vertically loaded piled rafts in layered cross-anisotropic viscoelastic saturated soils," Computers and Geotechnics, (2020), Vol. 119, pp.103-384.

[21] M. Y.Fattah, M. A.Yousif, S. M. K.Al-Tameemi, "Effect of pile group geometry on bearing capacity of piled raft foundations," structural engineering and mechanics, an international journal, techno-press journals, Korea, (2015), Vol. 54, No. 5, pp. 829-853. 